\title{
Drones and the Threshold for Waging War
}

\author{
Ezio Di Nucci, Associate Professor of Medical Ethics, University of Copenhagen
}

The case of military drones ${ }^{1}$ can serve as an example of the failure of philosophy to live up to the intricacies of the real world. In the dreams of some philosophers, drones are the perfect weapons. According to their advocates, they are meant to be precise in ways previously unimaginable and characterized by increased effectiveness and drastic reductions in collateral damage (Strawser 2013; Beauchamp \& Savulescu 2013). Yet, even if drones make it easier to wage war, the reason why they do so may not be the one commonly assumed within the philosophical debate among (military) ethicists namely, the promised reduction in casualties on either side. Rather, one could question whether drones, after all, lead to the prospects of reducing casualties - or if they, in fact, ultimately increase them. This paper will scrutinize the reasoning behind the arguments supporting the deployment of drones to search for alternative claims embedded in the political intricacies of international relations and domestic politics.

Not only can the military case for using drones appear to be rock solid, the ethical case for the deployment of drones seems to be, in principle, just as strong. From an ethical point of view, drones are supposed to be win-win. Those that deploy drones profit because of increased precision, effectiveness, speed and, crucially, the fact that drones are unmanned. Those features, in turn, increase operational possibilities and reduce risk - a strategist's dream. But also for the people living under them, drones can have significant advantages, in particular with respect to the promised reduction in collateral damage. In fact, there is evidence from both Pakistan and Libya about drones being welcomed by those attacked as well as by those attacking (see for example Beauchamp \& Savulescu 2013; Franke 2014). ${ }^{2}$ Even former President Obama has made the point that using drones in Pakistan is much more acceptable - to the Pakistanis themselves - than using ground troops or traditional aircraft.

Obama could consistently present himself as a pacificator (and win the Nobel Peace Prize) because his government conducted an increasing number of military

\footnotetext{
${ }^{1}$ A quick note about my terminology: I am using 'drones' just because it is the most common word for 'unmanned aerial vehicles' (UAV's), but my discussion is not restricted to aerial vehicles exclusively.

2 The situations and the different interests on the ground both in Libya and Pakistan are so complicated that it is very difficult to use this as solid evidence. Libyans and Pakistanis who welcomed the deployment of drones are not the same ones who are being targeted by drones.
} 
operations from within the wire of a US base. Thus, forget about boots on the ground, the drone pilots may just as well wear flip-flops. To be clear, this is a view that Obama has himself publicly expressed, for example in his 'Remarks by the President at the National Defense University' on May 23, 2013 (Franke 2014, 130). In that speech, Obama warned about the risk that manned operations would "lead [the US] to be viewed as occupying armies, unleash a torrent of unintended consequences," and "may trigger a major international crisis." As Franke (2014) plausibly points out, it is not hard to read Obama's words as a suggestion that drones are less controversial and therefore easier to use than traditional military forces. Thus, following that logic, everyone should be supportive of drone strikes: Not just perpetrators, but targets too; real people just as much as moral philosophers.

However, when calculating combat strategy, it is important not to forget about the actual political situation. Reality creeps in and spoils the philosopher's carefully constructed vision. In less than a decade, unmanned military drones have revolutionized the politics of war. In a way that is quite independent of their specific technical development, drones have become a symbol and placeholder for the technologization of war (and peace). Increasing automation, robotics, and artificial intelligence both within the military and civilian life are an extremely significant development, comparable to the possibilities facilitated by the Internet and digital revolution (Floridi 2014). Think about the actual data on collateral damage in Pakistan ${ }^{3}$ or the increasing asymmetry between the few countries that can afford the deployment of military drones. Without even having to add further examples, we obtain the following, simple dialectics: Starting from similar premises and aspirations - less war, less killing, less suffering ethical and political considerations seem to point in different, indeed opposite, directions.

The ethics of drones appears to suggest that we should welcome their deployment and wish for more drone operations and fewer old-fashioned, dirtier operations. However, the politics of drone deployment points to the idea that using drones will make it easier to wage wars and justify killing, which is also, ultimately, the case from a legal point of view (nowhere else other than in Plato's Republic do the moral philosophers, after all, make the laws). The aim of this paper is not, however, to replicate either the extensive ethical or the political debates on these subjects. ${ }^{4}$ Rather I would like to push this debate forward by looking at how we ought to compare and evaluate the different kinds of considerations within these debates. In doing so, the hope is to enter a dialogue in which we academics stop talking past each other and make our scholarly debates more visible for policy makers. I will pursue this effort by looking at

\footnotetext{
3 For some updated statistics, please see this recent article in Foreign Policy: http://foreignpolicy.com/2016/04/25/drones-kill-more-civilians-than-pilots-do/

4 The academic debate is extensive. See, for example: Singer 2009, Paust 2010, Strawser 2010, Brunstetter \& Braun 2011, Enemark 2011, Gregory 2011, Wall \& Monahan 2011, Byman 2013, Coeckelbergh 2013, Cronin 2013, Enemark 2013, Strawser 2013, Williams 2013, and Franke 2014. Also see Di Nucci 2014a, Di Nucci \& Santoni de Sio 2014, Santoni de Sio \& Di Nucci 2016, Di Nucci \& Santoni de Sio 2016 and Di Nucci forthcoming.
} 
one particular argument: That is the idea that drones make it easier to wage war - or, differently put, the thesis that drones lower the threshold for going to war.

Humanitarian Interventions and the Threshold for Waging War

We should not assume, however, that this consideration is necessarily used to argue against the development or deployment of drones. There is serious dispute in the literature about the idea that making wars easier to wage is essentially a bad thing. Zack Beauchamp and Julian Savulescu, for example, have used the idea that drones lower the threshold for waging war to argue that drones make humanitarian interventions both more likely and more effective. They suggest that "[...] lowering the threshold is not, as commonly assumed, necessarily a bad thing. In at least one case, the bug is in fact a feature: drones have the potential to significantly improve the practice of humanitarian intervention" (Beauchamp \& Savulescu 2013, 106).

Beauchamp and Savulescu make an interesting and well-documented case for how aversion to causalities among one's own soldiers can negatively influence the decision to intervene (they refer to the Clinton Administration's decision to stay out of Rwanda) as well as the effectiveness of those humanitarian interventions that do take place (in this case they refer to Kosovo). In the latter case, it is both in terms of the intervener's capability to prevent atrocities, but also in terms of collateral damages caused by the intervener (here Bosnia, which the authors do not discuss, may provide an even better example than Kosovo).

The point is supposed to be a simple one: With drones reducing or even eliminating one's own casualties we can expect more (and more effective) humanitarian interventions; thus, if we follow Beauchamp and Savulescu's argument, lowering the threshold for going to war is not necessarily a bad thing, it can actually have some significant positive consequences. There are four different elements to this argument:

a) The claim that drones reduce one's own casualties;

b) The claim that drones make war more likely;

c) The claim that (b) is true because of (a). Beauchamp and Savulescu refer to this as "the assumption that drones make war more likely by lowering the risk of casualties to the side employing them" $(2013,2)$.

d) The claim that (c) is not necessarily bad because humanitarian interventions are wars too.

Concerning (a) (“drones reduce one's own casualties") and (b) (“drones make war more likely"), I do not suggest that there is an equivalence between them. This is both because the latter would constitute, at best, a consequence of the former, but also because there may be other intervening factors. As it is evident in (c) ("drones make war more likely by lowering the risk of casualties"), Beauchamp and Savulescu do not 
keep these arguments apart. For my purpose, it is not particularly important to keep the two apart, which is why I have followed their formulation of 'making war more likely'. In my opinion, the interesting point in this argumentation is, however, not the one Beauchamp and Savulescu argue against - namely, that lowering the threshold for waging war is always or necessarily bad - but rather the question of whether lowering the threshold for going to war is, overall, something that we should welcome. Even once we have accepted that humanitarian interventions can be seen as wars and have also agreed that drones will bring about more (and more effective) humanitarian interventions, the question remains as to whether this positive development will compensate other possible negative consequences of a general lowering of the threshold. Namely, all the other wars which might otherwise not have been fought had drones not lowered the threshold.

In this context, the term 'wars' may, however, be misleading. The development that drones are speeding up military interventions precisely challenges the very concept of war. Due to the increased violence that drones allow for - i.e. targeted killings drone operations do not count as war in the traditional sense. One cannot deliver a reliable result by just comparing the number of just and unjust wars that would not otherwise have been fought had it not been for drones. That is, the unjust violence (that would not have been committed had it not been for drones) might not count as war, while the just violence - say humanitarian interventions - might still resemble traditional warfare. This is not the place to develop this point to any satisfactory extent, but it is worth remembering how drones may be changing our concepts related to what counts as war. I will, however, not press this point and move on to the other elements of the argument.

\section{Drones and the Reduction of Casualties}

I argue that (a) "drones reduce one's own casualties" is a plausible empirical claim, with the caveat that removing soldiers from the battle-space does not necessarily reduce one's own casualties since it can cause more civilian casualties back home through acts of terrorism. This is, again, a pretty simple point: Aversion to one's own casualties should not be seen as a point specific to military casualties, but just as one aspect in a much wider concern for one's own citizens. And if drones reduce operational casualties among military personnel and, in doing so, increase civilian casualties back home, then it would no longer be clear that (a) would still be true. Indeed, the truth of (a) would be very hard to establish, because it would depend on a comparative principle between the lives of one's own non-combatants and the lives of one's own combatants, not to speak of the difficulty of even defining these groups (see Fabre 2009).

The question of whether drones may increase one's own civilian casualties is, again, to a great extent an empirical one. Thus, I will not pursue it here in any great detail, but only state following more general observation: The decreasing availability of 
combatants (as targets) in the battle-space coincides with a significant and welldocumented increase of civilians in battle-space from NGOs and all sorts of private contractors to modern private military companies who should probably count as combatants (Liu 2015). ${ }^{5}$

The question of whether or not increased deployment of drones and other unmanned technologies may also increase civilian casualties among those countries that are deploying drones is not simply settled by looking at acts of terrorism. It also requires attention to what happens to the non-combatants of the deploying country (and maybe even its allies) in the battle-space. Certainly, it is not just a question of whether terrorism or acts of violence against non-combatants are increasing, but whether they are increasing because of the decreasing availability of combatants (as targets) in the battle-space, which drones and other technological developments are accelerating.

This issue is very interesting also from a normative point of view. One question is whether drones are increasing violence against the non-combatants of the deploying countries; an altogether different question is whether the decreasing availability of combatants (as targets) in the battle-space makes a difference to the normativity of violence against the non-combatants of the deploying country. It could be argued that because what used to be legitimate targets are being increasingly geographically removed from the battle-space, then targets that used to be illegitimate can increasingly become less so. One could object, however, that the geographical location of the enemy ought to make no difference to the legitimacy of attacking civilians or non-combatants. Drones do not change anything because non-combatants remain illegitimate targets while combatants under certain conditions (such as immediate threats) remain legitimate targets. So, the idea is that there is no normative difference - in terms of noncombatants' liability to be attacked - resulting from the development or deployment of drones.

This point is not quite obvious. As emphasized earlier, the increasing deployment of drones means fewer military personnel in the battle-space, but at the same time an increasing presence of civilians in the battle-space. But there is also another element, which is more specific to drones. Drone operators are now able to increasingly conduct a life that is much more similar to civilian life than to traditional military deployment, and they can do so while they still constitute an immediate threat for the enemy. This is because drone operators are able to live at home with their families and simultaneously fly deadly missions during working hours (Di Nucci \& Santoni de Sio 2016; Kirkpatrick 2016). It is an interesting question whether the fact that drone operators are now in war and yet able to mingle with non-combatants make those non-combatants liable to attack; for instance, in the form of collateral damage as a strike on a drone operator on her way to work. ${ }^{6}$ Of course, one could insist that drone operators are

\footnotetext{
${ }^{5}$ A further complication is that military personnel are increasingly being given peacekeeping and training tasks.

${ }^{6}$ On the ethics of collateral damages and double effect, see also Ethics Without Intention (Di Nucci 2014b).
} 
mostly liable to be attacked when they are active in service - and, as long as we hold on to this principle, ${ }^{7}$ there is no novelty and no normative difference. That would then mean, interestingly, that through technological development a country is not just materially increasing the safety of its combatants but also normatively diminishing their liability. ${ }^{8}$

\section{Why Do We (not) Go to War?}

The plausibility of (b) and (c) is worth considering in some detail. It may be that it is both true that 'drones reduce one's own casualties' and that 'drones make war more likely', but it may not be true that 'drones make war more likely because they reduce one's own casualties'. In other words, both (a) and (b) may be true while (c) could still be false if (b) is true independently of (a). In this context, Obama's speech serves as an example once more. Obama defends drone operations in Pakistan not by referring to their benefits in terms of risks to US troops, but rather by arguing that unmanned operations are more acceptable both for the country where (or against which) they are conducted and for the international community. Assuming that Obama is right about this, it could only be the case, if the reason why drone operations would be more acceptable is the fact of casualty reduction. But it is unlikely that this is what Obama was actually referring to, given his remark that traditional operations would "lead [the US] to be viewed as occupying armies." It is therefore much more likely that Obama was referring to drone operations being more acceptable over and above the reduction of casualties among own ranks. ${ }^{9}$ Interestingly, there is (as mentioned) some evidence from both Pakistan and Libya reporting it to be easier for local authorities to accept drone operations rather than other kinds of operations, which is supposedly what Obama may have been referring to. Additionally, drone operations are much more difficult for the media to report on, which again may at least in part explain why drones are taken to be easier to be accepted by the international community. Finally, since they are unmanned, drone operations are not subject to the same procedures and laws as other traditional operations.

\footnotetext{
${ }^{7}$ This principle may indeed be challenged. For example, there seems to be a broad acceptance of 'targeted killings' of enemies that are either of unclear combatant status or not actively involved in attacks (e.g. high profile leaders of terrorist networks). One may therefore raise questions about the 'moral equality of quasi-combatants.' But I do not have the space to address this here. Thanks to an anonymous referee for suggesting this.

${ }^{8}$ An example of this could be the following: While traditional soldiers may have been liable to attack while resting in their base and not actively in service, drone operators are not liable to attack while resting if they do so at home.

${ }^{9}$ Referring to what Obama may have meant rather than to what is true or right is, in this case, legitimate because Obama is the decision-maker. And the issue under discussion is the empirical one of whether or not drones will make wars more likely and why (rather than some related normative issue). So, given the issue, what decision-makers think is not just pertinent, but also decisive (with the caveat, obviously, that what Obama says in public may not necessarily reflect his (Administration's) views or reasons).
} 
These different elements share several important features: They may constitute reasons why drones make waging war easier and therefore lower the threshold for waging war (or 'state-sponsored violence') while also making no reference to reducing casualties in one's own ranks. These ideas may explain the (supposed) views of the Obama Administration. But it is different from that put forward by Beauchamp and Savulescu as it even allows for the following possibility: Namely, that drones do make waging war easier by lowering the threshold while at the same time increasing casualties in one's own ranks (say by causing more acts of terrorism against one's own non-combatants). Even though I have offered no evidence for this conclusion, the arguments that I have analyzed are not able to rule it out either. And this is significant since the scenario in which drones make wars easier to wage is, in a way, the worst possible outcome. In this scenario, both those who deploy drones and those against whom drones are deployed are losing. One reason to consider this a plausible outcome could be that civilian casualties due to terrorism would in a certain sense be better 'accepted' by the public than combatant casualties (and thus easier to 'sell') because it is simply less obvious that the former is a result of the government's military policies and strategies than the latter. $^{10}$

To sum up: We started from the idea that drones may be a win-win situation by promising advantages to both sides, but ended up not even being able to rule out the possibility that drones are, actually a lose-lose. Moreover, the philosophical assumption that drones will make wars more likely by reducing one's own casualties is not, it turns out, doomsday pessimism. It may actually be overly optimistic by misreading the politics of choosing drone operations over more traditional operations. This is, to be clear, not incompatible with Beauchamp and Savulescu's argument as they do not argue for the idea that drones make wars more likely by reducing one's own casualties, but rather assume this point to offer an evaluation of (some) of its consequences. Still, my argument questions not only their assumption but their general claim, which is prominent in the debate on drones: This is not simply the coarse claim that 'drones make war more likely,' but also the more fine-grained version of it according to which 'drones make war more likely by reducing one's own casualties.' Thus, Beauchamp and Savulescu may be right, and indeed I have no objections to the content of their argument. Symptomatically, though, they may have made their argument irrelevant (or anyway less interesting) by misreading political realities on the ground, in particular in respect to how important casualty reduction actually is for decisions on war and peace. ${ }^{11}$

\footnotetext{
${ }^{10}$ Thanks to an anonymous referee for this suggestion.

${ }^{11}$ In future research, it will also be worth thinking about the relative importance of various kinds of casualties, such as enemy combatants, friendly combatants, enemy civilians, friendly civilians, agents of contested status etc. (see Fabre 2009). This can and probably should be done, as this article suggests, not only in terms of military ethics and just war theory, but also in terms of the effect that these differences can have in perceived acceptability and political decision-making. Again, thanks to a referee for this suggestion.
} 


\section{References}

Beauchamp, Z \& Savulescu, J 2013, 'Robot Guardians: Teleoperated Combat Vehicles in Humanitarian Military Intervention', in B J Strawser (red.), Killing by Remote Control: The Ethics of an Unmanned Military, Oxford, Oxford University Press.

Brunstetter, D \& Braun, M 2011, 'The Implications of Drones on the Just War Tradition', Ethics \& International Affairs, vol. 25, no. 3, pp. 337-358.

Byman, D 2013, 'Why Drones Work'. Foreign Affairs, vol. 92, no. 4, pp. 32-43.

Coeckelbergh, M 2013, 'Drones, Information Technology, and Distance: Mapping the Moral Epistemology of Remote Fighting, Ethics and Information Technology, vol. 15, no. 2, pp. 87-98.

Cronin, A K 2013, 'Why Drones Fail', Foreign Affairs, vol. 92, no. 4, pp. 44-54.

Di Nucci, E 2014a, 'I droni tra progresso ed etica', AREL La Rivista, vol. L, pp. 108115.

Di Nucci, E 2014b, Ethics Without Intention, London, Bloomsbury.

Di Nucci, E (forthcoming), 'Sexual Rights, Disability and Sex Robots', in J Danaher \& N McArthur (eds.), Philosophy and Ethics of Sex Robots, MIT Press.

Di Nucci, E \& Santoni de Sio, F 2014, 'Who's Afraid of Robots? Fear of Automation and the Ideal of Direct Control', in F Battaglia \& N Weidenfeld (red.), Roboethics in Film, Pisa University Press.

Di Nucci, E \& Santoni de Sio, F 2016, Drones and Responsibility, New York and London, Routledge.

Enemark, C 2013, Armed Drones and the Ethics of War: Military Virtue in a PostHeroic Age, Routledge.

Enemark, C 2011, 'Drones over Pakistan: Secrecy, Ethics, and Counterinsurgency', Asian Security, vol. 7, no. 3, pp. 218-237.

Fabre, C 2009, 'Guns, Food, and Liability to Attack in War', Ethics, vol. 120, pp. 3663.

Floridi, L 2014, The Fourth Revolution. How the Infosphere is Reshaping Human Reality, Oxford, Oxford University Press.

Franke, U E 2014, 'Drones, Drone Strikes, and US Policy: The Politics of Unmanned Aerial Vehicles, Parameters, vol. 44, no. 1, pp. 121-131.

Gregory, D 2011, 'From a View to a Kill. Drones and Late Modern War, Theory, Culture \& Society, vol. 28, no. 7-8, pp. 188-215.

Kirkpatrick, J 2016, 'State Responsibility and Drone Operators', in E Di Nucci \& F Santoni de Sio (red.), Drones and Responsibility, New York and London, Routledge.

Liu, H Y 2015, Law's Impunity, Hart.

Paust, J J 2010, 'Self-defense Targetings of Non-State Actors and Permissibility of US use of Drones in Pakistan', Journal of Transnational Law \& Policy, vol. 19, no. 2, p. 237. 
Santoni de Sio, F \& Di Nucci, E 2016, 'Drones and Responsibility: Mapping the Field', in E Di Nucci \& F Santoni de Sio (eds.), Drones and Responsibility, New York and London, Routledge.

Singer, P W 2009, Wired for War, New York, Penguin Books.

Strawser, B J 2010, 'Moral predators: The Duty to Employ Uninhabited Aerial Vehicles', Journal of Military Ethics, vol. 9, no. 4, pp. 342-368.

Strawser, B J (red.) 2013, Killing by Remote Control: The Ethics of an Unmanned Military, Oxford, Oxford University Press.

Wall, T, \& Monahan, T 2011, 'Surveillance and Violence from afar: The Politics of Drones and Liminal Security-Scapes', Theoretical Criminology, vol. 15, no. 3, pp. 239-254.

Williams, B G 2013, Predators: The CIA's Drone War on al Qaeda, Potomac Books. 